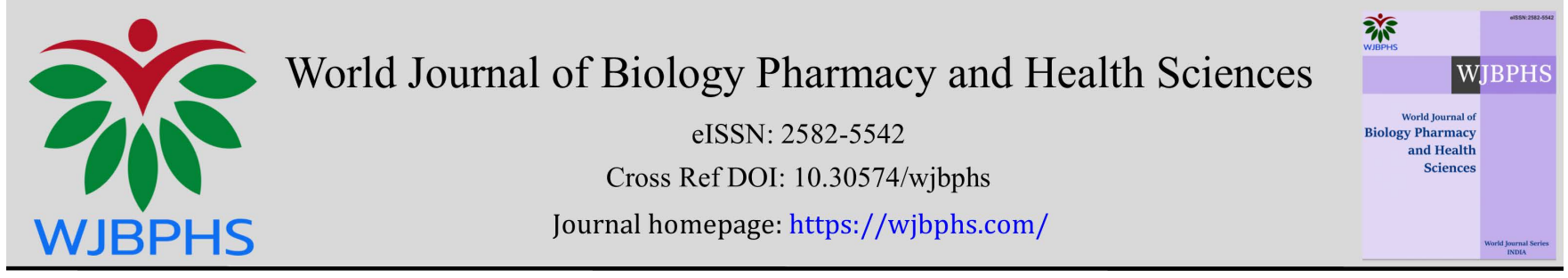

(REVIEW ARTICLE)

\title{
Apoptosis, guardian of the genome: Review
}

\author{
Ahmad Mohammad Khalil * \\ Department of Biological Sciences, Yarmouk University, Irbid. Jordan.
}

World Journal of Biology Pharmacy and Health Sciences, 2021, 05(01), 037-054

Publication history: Received on 01 January 2021; revised on 08 January 2021; accepted on 10 January 2021

Article DOI: https://doi.org/10.30574/wjbphs.2021.5.1.0003

\begin{abstract}
Apoptosis has attracted great attention in the last two decades and the number of publications related to apoptosis has been growing exponentially. The revolution that has occurred in apoptosis research is a direct result of a better understanding of the genetic program and biochemical mechanisms of apoptosis. Apoptosis is not only a common normal event but also essential for the growth and development of organisms. In the adult, apoptosis is mostly abnormal, but in its absence or failure cancer cells obtain immortality by escaping this type of cell death. Apoptosis works synergistically in intrinsic and extrinsic pathways. The first pathway is initiated by the cell itself in response to stress. The second is initiated via death receptors stimulated by cells of the immune system. This review is an attempt to answer questions like: Why is cell death important to study? How cells undergo apoptosis? What controls the decision between life and death? Which cellular events could cause the control of apoptosis to be impaired? The literature cited below shows some sort of unity in the scientific community on the necessity of a sophisticated balance between "prosurvival" and "pro-death" forces to ensure the happiness of cells in multicellular organisms
\end{abstract}

Keywords: Apoptosis; Anti-cancer drugs; Caspases; Cell death; Intrinsic/extrinsic pathway; Embryo development; Cancer development.

\section{Introduction}

Cell death has been classified into three types; apoptosis, autophagy, and necrosis [1]. It has been suggested that the three types of cell death; should not be studied separately as independent processes, since they are interconnected with overlapping signaling pathways and cross-talk in response to different stresses [2-3]. Scientists believe that necrosis is an inappropriate term to describe a mechanism of cell death because necrosis refers to the degradative processes that occur after cell death. Instead, they suggest to use "oncosis", which means swelling, to describe a process that leads to necrosis. Another point worth mentioning is that the term "autophagy" represents another mechanism for programmed cell death and, similar to apoptosis [4]. Autophagy is the process of self-digestion and degradation of proteins, organelles, and cell to obtain essential elements and energy for cell survival. However, the concept of autophagic cell death has been a matter of debate within the scientific community [5]. While writing this review a newly identified form of cell death (Ferroptosis) was encountered [6]. Ferroptosis is a regulated necrosis process and driven by irondependent lipid peroxidation and could be mediated by energy stress [7-8]. The present review will focus on the general overview of apoptosis. Most of the reviews focused on a specific arm of the field. The volume of the accumulated information on the subject in the literature is very huge [5, 7-17]. With an eye towards broader coverage of the subject, this review briefly discusses selected aspects of apoptosis: techniques commonly used to detect and count apoptotic cells, the phases and mechanisms of apoptotic death as well as the delicate balance between the pro- and anti-apoptotic wings of the process during development. The discussion will be extended to cover the health consequences of the disruption of this balance in relation to drug development and discovery.

\footnotetext{
${ }^{*}$ Corresponding author: Ahmad Mohammad Khalil

Department of Biological Sciences, Yarmouk University, Irbid. Jordan.
} 


\section{Apoptosis versus necrosis}

The term apoptosis, In Greek "leaves falling", was coined in 1971 [18]. The biological meaning of apoptosis is the elimination of damaged cells. The major molecular players in apoptosis have been identified and the biochemical pathway that regulates this form of death has been dissected. The cellular morphology that distinguishes apoptosis from necrosis (Greek. Nekros - dead) is a vital incidence for the advancement of the field of cell death. Table (1) and Figure (1) summarize the basic morphological and biochemical differences between apoptosis and necrosis. Usually several hours are needed from the initiation of cell death to the final cellular fragmentation. However, the time taken varies depending on the cell type, the stimulus and the apoptotic pathway [5, 10, 15, 21-22].

\section{Methods for detecting apoptosis}

Techniques for detecting apoptotic cells allow the development of more effective, and therefore better-tolerable therapeutic approaches. Various means of detecting apoptotic cells have been explored and made available over the time for demonstrating and counting apoptotic cells [5, 22-23]. All these strategies have contributed, from different perspectives, to the identification of apoptosis and to its distinction from necrosis. These most commonly used methods include viability analysis, luminescent assays for measuring caspase activity, mitochondrial assays, immunohistochemistry, and flow cytometry. Detailed protocols and background information about these methods are out of the scope of this review, but can be reached elsewhere [9, 22, 24-25].

\subsection{Microscopy}

Determination of the morphological features of cell death by microscopy is an important to discriminate apoptotic and necrotic cells, but it is very subjective and time-consuming [26]. In contrast, other methods analyze biochemical and morphological features of dying cells directly in one measurement by combining classical flow cytometry and microscopy. This allows for the quantification of several thousand cells in a short time, together with an objective analysis of pictures by image-based features [27]. In general, the light microscopy approach can provide both qualitative and quantitative data. Morphological changes both of the nucleus and the cytoplasm of cells undergoing apoptosis are remarkably similar across cell types and species. Methods to detect chromatin condensation for whole cells include Hematoxylin and eosin stain (Figure 2a) and deoxynucleotidyl transferase-mediated dUTP nick-end labeling (TUNEL) staining (Figure $2 \mathrm{~b}$ and $2 \mathrm{c}$ ). More detailed changes in apoptotic cells can be observed with electron microscopy (Figure 3).

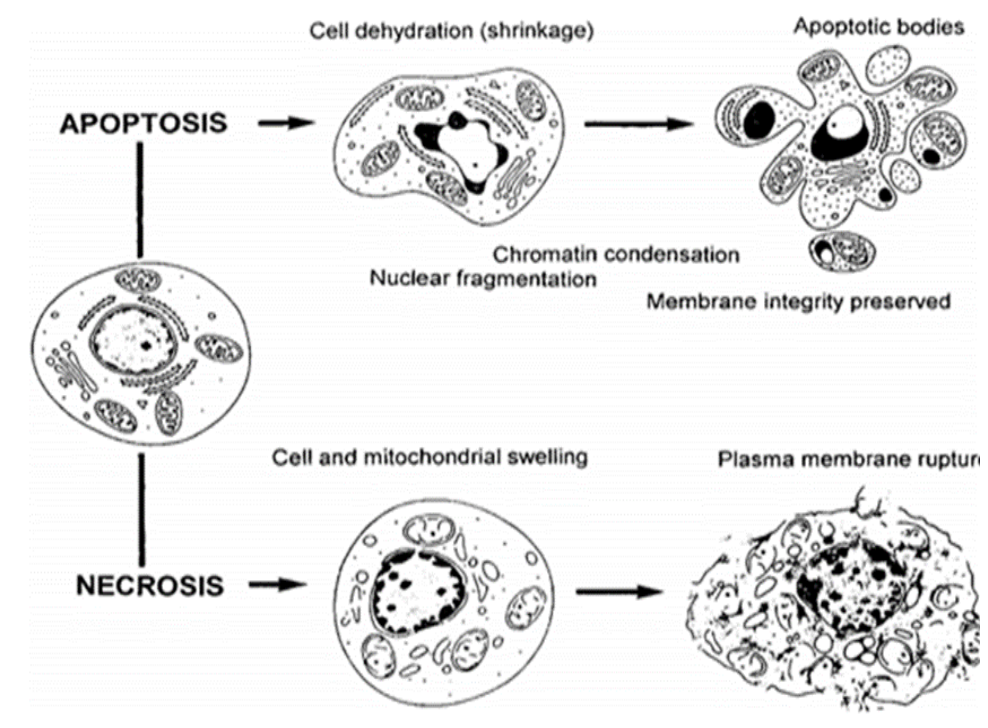

Figure 1 Diagrammatic illustration apoptosis versus necrosis. Apoptosis above: Chromatin condensation, nuclear fragmentation, bleb off in plasma membrane, apoptotic body formation and final phagocytosis. Necrosis below: Swelling of organelles and leakage of cellular components and final cell lysis [9]. 
Table 1 The main morphological biochemical differences between apoptosis and necrosis [5, 15, 19-21].

\begin{tabular}{|c|c|c|}
\hline Aspect of comparison & Apoptosis & Necrosis \\
\hline Nature of the process & $\begin{array}{l}\text { A genetically programmed cell death } \\
\text { occurring due to cellular signals } \\
=\text { normal, appropriate, natural or } \\
\text { controlled physiological process }\end{array}$ & $\begin{array}{l}\text { A non-programmed premature cell } \\
\text { death occurring due to injury or } \\
\text { disease } \\
=\text { abnormal, inappropriate or } \\
\text { uncontrolled pathological process. }\end{array}$ \\
\hline Triggered by & $\begin{array}{l}\text { Activation of cell-suicide cysteine } \\
\text { proteases called caspases. }\end{array}$ & $\begin{array}{l}\text { In part by endogenous release of } \\
\text { intracellular } \\
\text { Ca++ produced by ion failure }\end{array}$ \\
\hline Membrane potential & $\begin{array}{l}\text { No sodium influx; no change in potassium } \\
\text { concentration in cell }\end{array}$ & $\begin{array}{l}\text { Potassium loss; sodium entry; fall in } \\
\text { membrane potential }\end{array}$ \\
\hline $\begin{array}{l}\text { Integrity of cell } \\
\text { membrane }\end{array}$ & Remains intact & $\begin{array}{l}\text { Swells up leading to rupture of the } \\
\text { cell. }\end{array}$ \\
\hline Leakage of cell contents & $\begin{array}{l}\text { Cytoplasmic components are kept inside } \\
\text { the cell. }\end{array}$ & $\begin{array}{l}\text { Contents of the cytoplasm released } \\
\text { out of the cell }\end{array}$ \\
\hline Cell size & Cells shrink and decrease in size & Cells swell and increase in size \\
\hline $\begin{array}{l}\text { cytoplasmic } \\
\text { vacuolization }\end{array}$ & $\begin{array}{l}\text { Cytoplasm and nucleus } \\
\text { break up, blebs form on membrane and } \\
\text { bud off to form apoptotic bodies }\end{array}$ & $\begin{array}{l}\text { Cytoplasmic vacuolization occurs } \\
\text { with breakdown of organelles. }\end{array}$ \\
\hline $\begin{array}{l}\text { Nuclear and DNA } \\
\text { fragmentation }\end{array}$ & $\begin{array}{l}\text { Nucleus condenses and becomes pyknotic } \\
\text { (shrink). Nuclear envelop breaks down. }\end{array}$ & $\begin{array}{l}\text { Nucleus breaks up and becomes } \\
\text { multi-nucleated'. Nuclear envelop } \\
\text { does remains intact. }\end{array}$ \\
\hline $\begin{array}{l}\text { Appearance of DNA in } \\
\text { agarose gel }\end{array}$ & $\begin{array}{l}\text { Ladder-like DNA bands due to DNA pre- } \\
\text { lytic fragmentation }\end{array}$ & $\begin{array}{l}\text { No bands DNA smashed/smeared due } \\
\text { to post-lytic DNA digestion }\end{array}$ \\
\hline Fate of cellular residues & $\begin{array}{l}\text { Dying cells secrete factors the recruit } \\
\text { phagocytes. Cells are phagocytosed or } \\
\text { digested by neighbouring cells or } \\
\text { phagocytes, such as glial cells and } \\
\text { macrophages. }\end{array}$ & $\begin{array}{l}\text { Cell lyses (Ingested by phagocytes), } \\
\text { eliciting } \\
\text { an inflammatory } \\
\text { auto-immune response }\end{array}$ \\
\hline $\begin{array}{l}\text { Number of cells } \\
\text { affected }\end{array}$ & Individual cells appear affected & $\begin{array}{l}\text { Whole areas of the tissue are affected } \\
\text { (Loss of functional tissue. } \\
\text { Impaired organ function, transient or } \\
\text { permanent). }\end{array}$ \\
\hline Energy requirement & ATP dependent (active process) & $\begin{array}{l}\text { Energy input not required (passive } \\
\text { process) }\end{array}$ \\
\hline Caspases requirement & Caspases-dependent pathways & Caspases-independent pathways \\
\hline
\end{tabular}




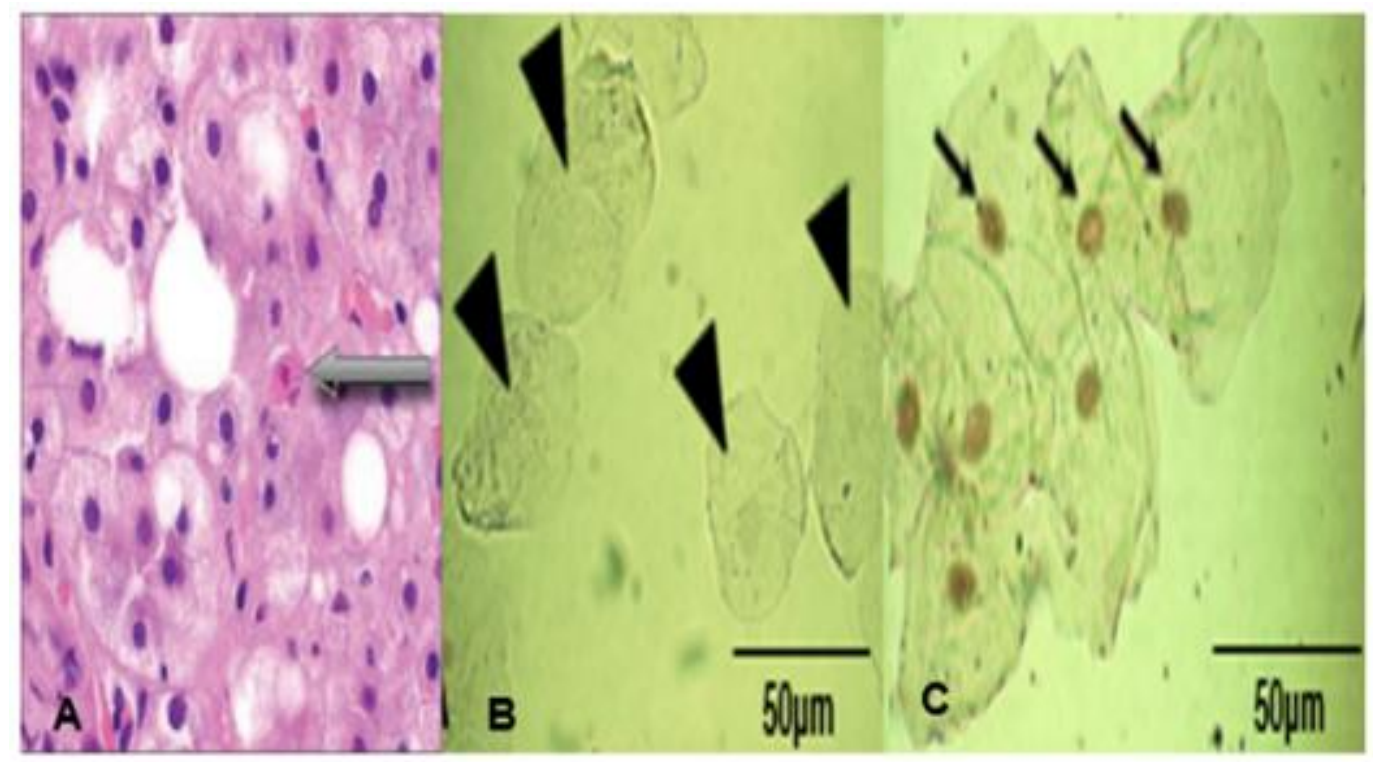

Figure 2 Light microscope photographs of (a) H and E stained liver specimen showing an apoptotic hepatocyte (Grey arrow). The cell appears as a round or oval mass with dark eosinophilic cytoplasm and dense purple nuclear chromatin fragments [22]. Exfoliated buccal mucosal cells stained according to TUNEL assay. (b) Arrow heads indicate negative (normal healthy cells). (c) Arrows indicate condensed strong positive TUNEL test (apoptotic cells). (The b and c Magnification 400 X) [28].
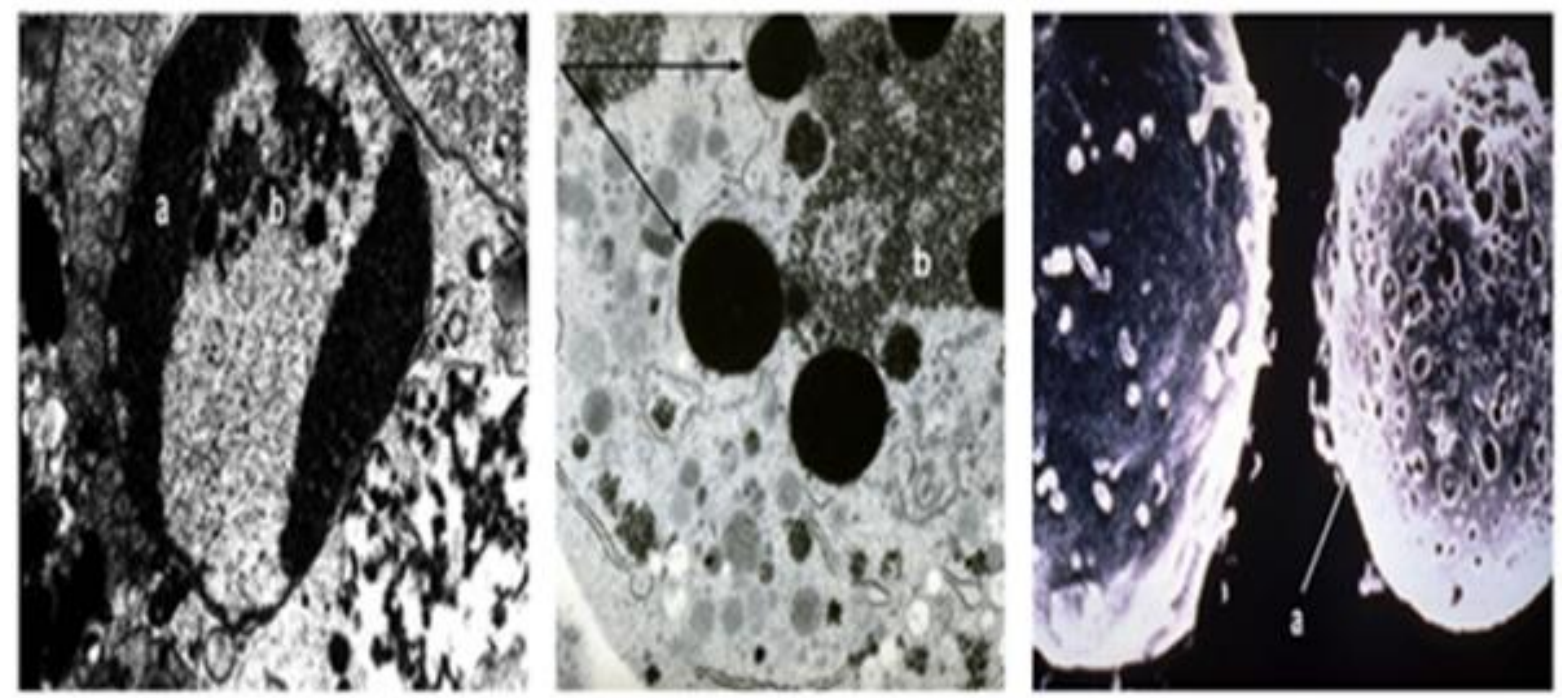

Figure 3 Transmission electron micrographs of an apoptotic cell showing marked chromatin condensation at the nuclear periphery (Left) and a fragmented nucleolus. (Middle). Separate aggregates of chromatin (a) free within the cytoplasm. (b) Ribosomes are also present, and all elements are packaged as membrane-bound apoptotic bodies. Right: Scanning electron micrograph showing smoothening and loss of microvilli on the cell surface puckering [23].

\subsection{Agarose gel electrophoresis}

Characteristic DNA feature of apoptotic DNA fragmentation can be regarded as a biochemical definition of death [22]. When the DNA of apoptotic cells is run on agarose gel to separate DNA fragments based on size, a unique nuclear ladder of bands is obtained (Figure 4). In contrast, the DNA from necrotic cells is degraded haphazardly and appears as a smear [23]. 


\section{Cell biology and biochemistry of apoptosis}

\subsection{Cysteine-aspartic-acid-proteases (caspases)}

Caspases are central to the mechanism of apoptosis. Human caspases are a family of 12 fate-enzymes which are generally divided into two classes: those related to caspase 1 (e.g. caspase-1, $-4,-5,-13$, and -14) [5]. This class is mainly responsible for cytokine processing during inflammatory activities. The second includes caspase-2, $-3 .-6,-7,-8,-9$ and 10 which are involved in apoptosis. The second group is further subdivided into initiator caspases (e.g. caspase-2, -8, 9 and -10) and execution (effector) caspases (caspase-3, -6 and -7). Caspase- 3 and -7 have been placed at the center of a fundamentally recursive apoptotic program, where they function as redundant signal amplifiers, essential for activation of both upstream and downstream apoptotic processes and efficient cell death [29-31].

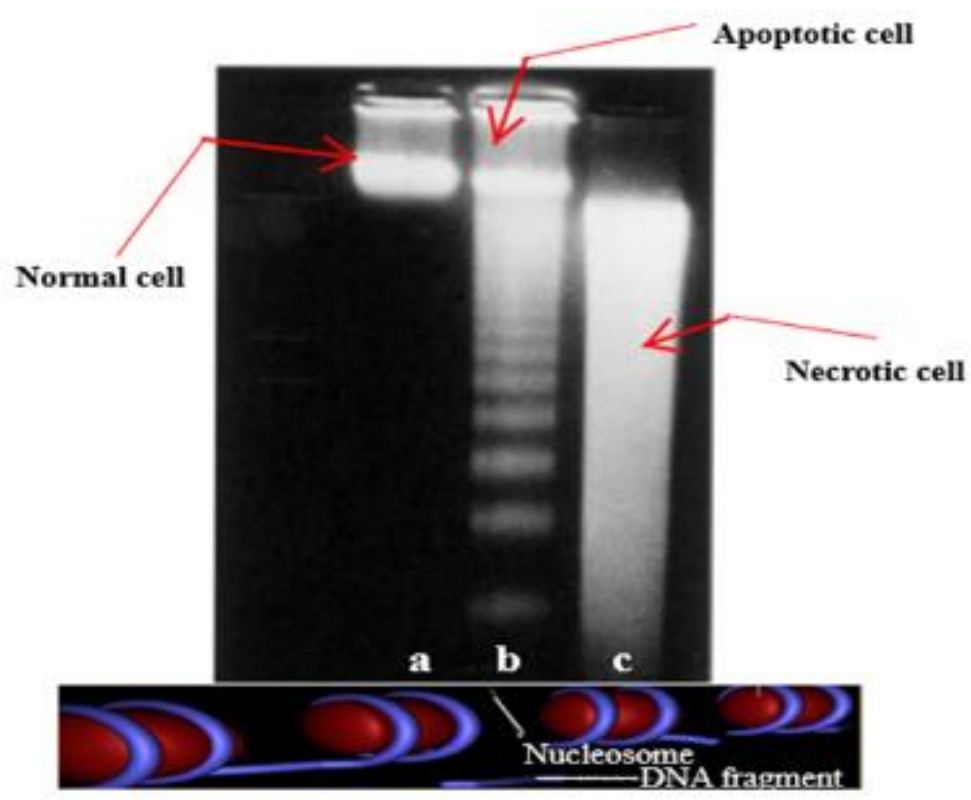

Figure 4 Agarose gel showing the appearance of DNA extracted from a) Normal cells; b) Apoptotic cells with characteristic "DNA ladder" banding pattern and c) Necrotic Cells [22]. Below panel: DNA cleaves into oligonucleosomes in multiples of 180 to 200 base pairs (oligonucleosomal ladders) by endonucleases in apoptotic cells.

Protease activation have been described in detail mainly for nematode. Knowledge of protease involvement in apoptosis in human, and mice models of apoptosis, is fragmentary [32]. However, recent studies have revealed that caspases are conserved across species and the mechanism of caspase activation and inhibition is also conserved. Caspases have to be tightly regulated since their inappropriate activation can lead to severe consequences. The first level of caspase control is observed in their structure and activation. Caspases are synthesized as inactive precursors; activated by proteolytic cleavage [31-32]. There a minimal two-signaling carefully monitored mechanism of caspase activation (Figure 5). The initiator caspases are activated within oligomeric signaling complexes in response to apoptotic stimuli. Once activated, the initiator caspases directly activate the executioner (caspases by limited proteolytic cleavage. A second level of regulation involves the specific inhibition of active caspases by naturally occurring cellular inhibitors (Inhibitor of apoptosis proteins; IAPs)). The distinct activation machineries explain how an apoptotic stimulus is converted to proteolytic activity, and how this activity is amplified to permit limited proteolysis of tenths of protein substrates whose cleavage is needed for effective apoptosis [10, 32]. 


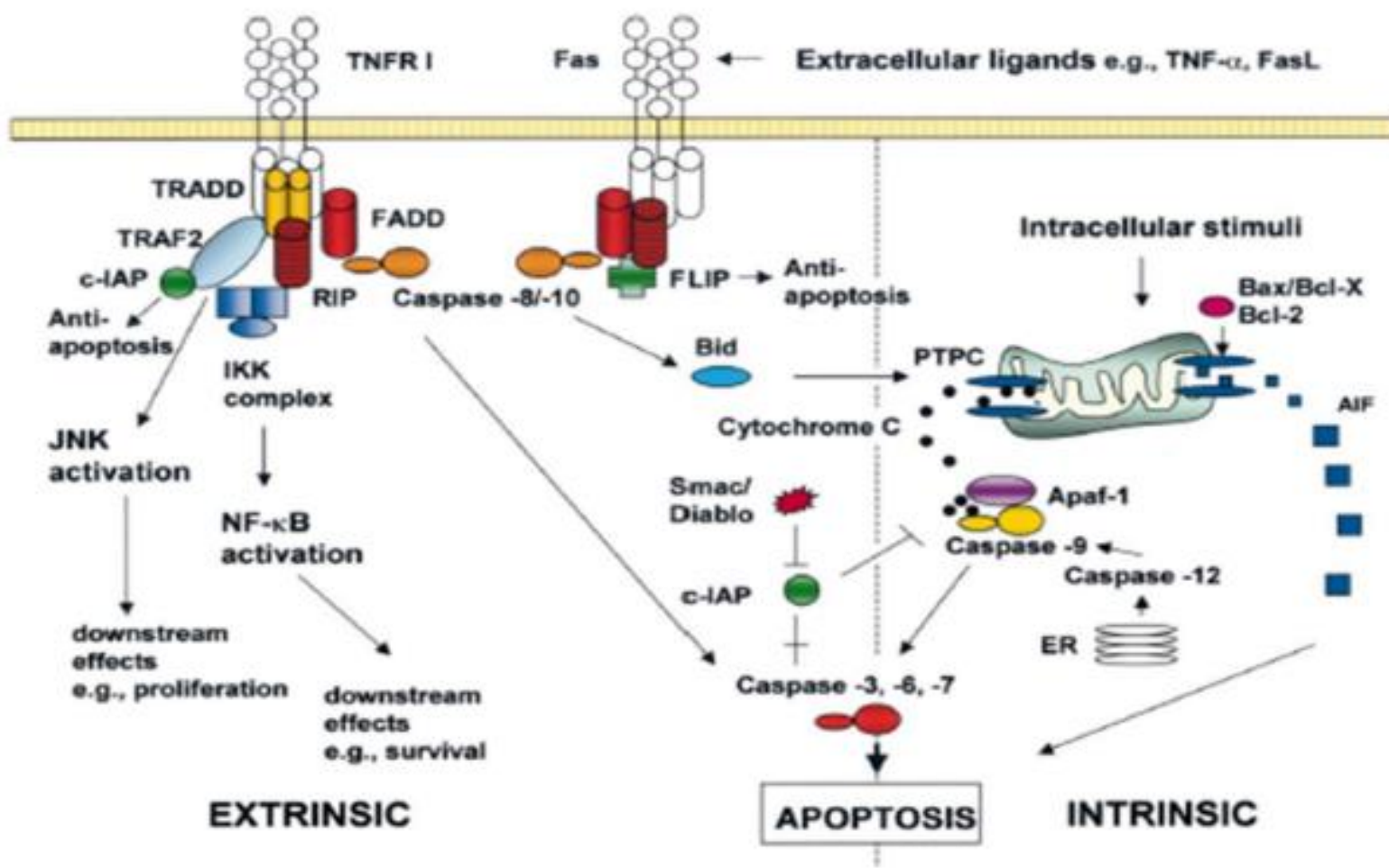

Figure 5 Apoptosis can be triggered by either extrinsic (extracellular) or intrinsic (intracellular or mitochondriadependent) stimuli. Extrinsic death receptor-mediated pathway is stimulated by external cytokines and is mitochondria-independent. Death receptor signaling may involve direct caspase-8-mediated caspase-3 activation or a Bid-cleavage-dependent mitochondrial amplification step. Each pathway activates its own initiator caspases which in turn will activate the executioner caspase-3. The execution pathway results in characteristic cytomorphological features (Figure 6) [10].

\section{Stages of the apoptotic death}

Apoptosis controls a dynamic interplay between pro-death and pro-survival mechanisms. Depending on the origin of the apoptotic signal, there are three pathways by which caspases can be activated. The two commonly described apoptotic pathways [32-33] are the intrinsic and extrinsic (death receptor-mediated) pathways (Figure 5). The two eventually converge to a common pathway of a caspase activation cascade or the execution phase of apoptosis. A third less well-known initiation pathway is the intrinsic endoplasmic reticulum (ER) pathway and is related to unfolding of proteins and reduced protein synthesis in the cell [34-36].

\subsection{Initiation of apoptosis}

In this phase cells are committed to die due to withdrawal of positive signals such as growth factors (GFs) for neurons and Interleukin-2 (IL-2) for T cells [32]. Commitment to death may be a consequence of reception of negative signals such as increased levels of oxidants within the cell, damage to DNA by oxidants or death activators. The process can be reversed under certain cellular conditions.

\subsubsection{Extrinsic phase}

This phase (recognition of cells to be killed) is stimulated when natural killer T lymphocytes and macrophages. These cells normally express molecules called death ligands (DL) on their surfaces, which recognize target cells, either by ligation of the DLs to the death receptors (DRs) on the surface of these cells, or by secretion of cytolytic molecules (i.e. perforin and granzyme) [37]. Adaptor proteins cause initiator procaspases to cluster together leading to a conformational change that activates the procaspases. A family of DRs has been described, e.g. Fas (also known as DR2, CD95 or AP0-1) and TNF-R, as well as ectodysplasin A receptor (EDAR) and nerve growth factor receptor (NGFR). These genuine DRs are clustered on the cell surface of the target cells. Intracellularly, these receptors possess a death domain (DD) and when triggered by a cell death signal, a number of molecules are linked to the DD, resulting in the activation 
of a signaling cascade; apoptosis-inducing machinery. The cytosolic adaptor Fas-associated protein with DD (FADD), also called mediator of receptor-induced toxicity 1(MORT1) that is induced by DRs, such as Fas is essential for Fasinduced apoptosis. The Tumor Necrosis Factor Receptor (TNFR) -associated death domain (TRADD) was found associated with TNF-R1 upon binding of TNF $\alpha$. The DD-containing molecules are specialized adapter molecules coupling to the apoptosis executioners, which are in many instances members of the caspase family of proteases [37-38]. The best characterized member of these receptor-binding caspases is caspase-8. It is recruited to the CD95 DISC by the adaptor FADD [37-38].

\subsubsection{Intrinsic phase}

Cell viability is maintained by the GFs promoted synthesis of anti-apoptotic molecules such as B-cell lymphoma-2 (Bcl2) $[10-11,39]$. Bcl-2 proteins play an essential role in the regulation of the intrinsic pathway as they reside upstream of irreversible cellular damage and act mainly at the mitochondria level (Figure 5). Intrinsic apoptosis is activated by DNA damage, binding of nuclear receptors by glucocorticoids, heat, radiation, GFs or hormones deprivation, viral infection, hypoxia, and increased intracellular calcium concentration (Figure 5). When cells are subjected to stress Bcl-2 are lost. These stimuli activate BH3-only proteins, which promote the assembly of Bcl2-antagonist/killer-Bcl2 associated X (BakBax) oligomers. Bax and Bak are directly responsible for the loss of mitochondrial outer membrane (MOM) integrity. The MOM permeability increases resulting in release of pro-apoptotic molecules into the cytoplasm (cytochrome C) and leads to caspase activation and apoptosis. In the cytosol, cytochrome c binds to Apaf-1 to form a structure known as the apoptosome, which recruits procaspase 9 and activates it to caspase 9. Active caspase-9 then directly cleaves and activates effector caspases, such as caspase-3 (Figure 5).

\subsubsection{Execution phase}

5.1.4. Apoptosis results in dramatic morphological and biochemical changes in the dying cell (degradation of dead cells) due to systematic disassembly of cellular architecture and functional pathways (Figure 6). The dismantling of an apoptotic cell into subcellular fragments and the clearance of the apoptotic bodies is a hallmark of apoptosis [13, 3942]. In contrast to the initiation phase, the execution phase is irreversible. Mitochondrial pro-apoptotic factors such as Apoptotic-inducing factor (AIF), Oxidorductase (WOX1) and Endonuclease G (Endo G) [11] traverse the NE during apoptosis and exert their effects on the nucleus leading to fragmentation of the nuclear lamins and nuclear breakdown. Examples of other proteins that are cleaved by caspases during apoptosis are emerin, spectrin, fodrin, $\beta$-catenin, gelsolin ... etc. These proteins are engaged in the maintenance, organization, and attachment of the cytoskeleton (e.g., an actin digesting protein; gelsolin). Cytoplasmic DNase is converted to an active form and the DNase causes characteristic internucleosomal cleavage of DNA (Figure 4).

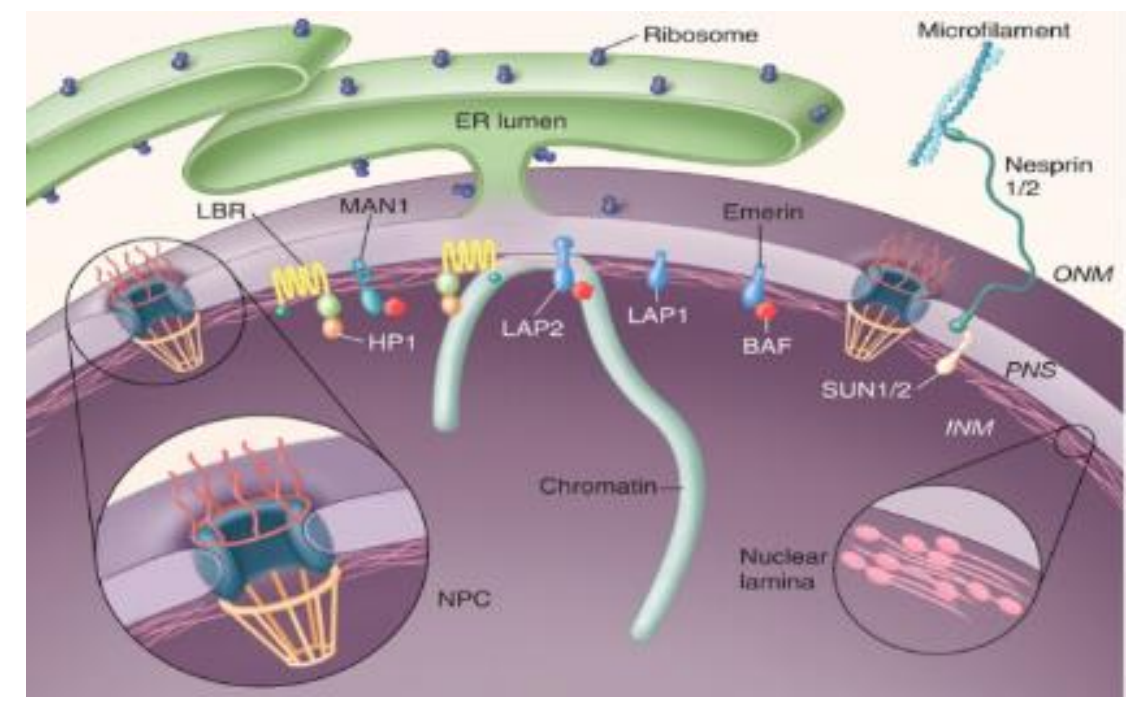

Figure 6 Nuclear envelope organization showing selected inner nuclear membrane (INM) lining proteins, including lamina-associated polypeptides 1 and 2 (LAP1 and LAP2) and LBR, these proteins interact with HP1 and BAF and give links to chromatin. The nuclear outer membrane (NOM), which is continuous with the ER, is characterized by cytoskeleton-associated nesprin proteins that are tethered by Sun1 and Sun2 in the INM. The activity executioner caspases 3,6, and 7 results in the controlled destruction of the actual targets in the cell to execute apoptosis. Caspases 
target: FAK (focal adhesion kinase): inactivation of FAK disrupt cell adhesion, leading to detachment of the apoptotic cell from its neighbours [41].

\subsubsection{Phagocytosis phase}

The final stage of apoptosis involves phagocytosis and degradation of the apoptotic bodies by macrophages followed by digestion within phagolysosomes [5, 43-44]. Destruction of apoptotic cells very rapidly, within minutes or a few hours, triggers neighboring cells like CD14 cells to recognize cells "corpses" followed by the rapid clearance of the apoptotic bodies by phagocytic cells. That is why apoptosis is rarely seen in situ without being observed both at the macro- and microscopic levels. This important swift elimination somehow prevents the occurrence of an inflammatory process which characterizes necrotic death.

\subsection{Genetic control of apoptosis}

Apoptosis involves highly complicated, genetically coded mechanisms. The first breakthroughs in apoptosis research came from the apoptotic genes in the nematode Caenorhabditis elegans [45]. In this worm 1090 somatic cells are involved in the formation of the adult, of which 131 cells undergo apoptosis. It has been indicated that mutations that block or partially cause loss of function of apoptotic genes in C. elegans embryos enhance cell survival of some cells that are originally programmed to die [45]. Interestingly, homologs of these apoptotic genes also function to control apoptosis in other multi-cellular organisms indicating that apoptosis is a "built-in ability" process of highly conserved evolutionary origin $[4,46]$.

\subsubsection{Embryo development}

Apoptosis is involved in fundamental biological such as development, differentiation, proliferation/homoeostasis, regulation and function of the immune system [47]. Inactivation of the death pathway is almost lethal in animals with indeterminate cell number (in these animals the cell number is not regulated so exactly). Normal development involves a dynamic interplay between pro-death and pro-survival signaling mechanisms that make decision regarding a cell's fate [48]. This allows body structures to grow and develop correctly maintaining a constant number of cells [46]. It appears that during development of most organs and tissues more cells are produced than those that contribute to the final organism [49]. It is better to have a mechanism that produces more cells than necessary and then eliminate the excess than to produce too few cells and thus run the risk of making an incomplete organism. Once the organ reaches a size where survival factors become limiting, cell death starts to play, so that it is ensured that the organ does not grow out of control. Thus, the cell intrinsic mechanisms of apoptosis is needed to regulate the death of their cells to (1) limit the sizes of cell populations in adult bodies and the number of times it can divide (both timing and number of cell divisions are modulated through cell cycle); cell proliferation must be balanced with cell death (Homeostasis). (2) Allow organisms to precisely control mechanisms that depend on signaling and cell interaction to coordinate the survival, growth and division of cells (most cells die if they fail to receive survival signals from other cells).

During neurogenesis, neuronal cell division is primarily restricted to embryonic development. In utero, vertebrate embryos produce vastly more numbers of neural precursor cells than are needed [48-49]. These cells differentiate into post-mitotic neurons, which then grow and extend their axons to innervate target regions. Neurogenesis involves mass suicide of all the extra neurons those that have not developed the necessary connections with target cells producing limited amounts of survival-mediating GFs (Figure 7a and 7b). Competition among innervating young neurons for neurotrophic factors is crucial in the selection of surviving vs. dying neurons, and the limited amount of these factors appears to determine the extent of cell death [50].

Basically, cell death is a general and convenient way to delete cells that should no longer be part of the organism [51]. Metamorphosis of the tadpole into adult toad (Figure 7c) is accomplished by resorption of the tadpole tail as well as removal of gills and even fins from the body during its transformation into an adult. Failure of this process will produce a clumsy organism unable of adapting to the environment. It has been shown that inhibition of macrophages can disrupt the remodeling of tissues in the tadpole tail during regression [50-51]. It appears that the engulfing cells may act to make sure that cells triggered to undergo apoptosis will die rather than recover after the initial stages of death [52]. 

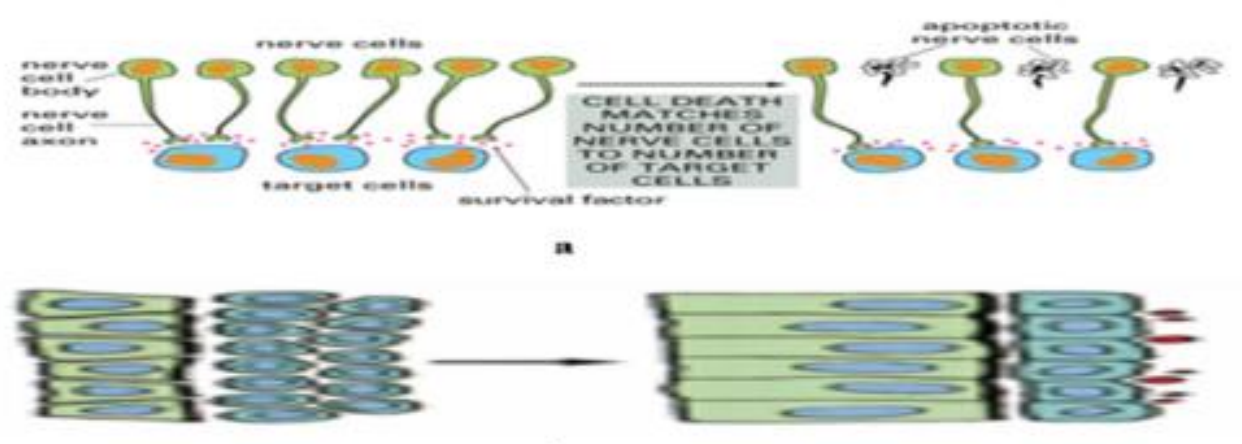

b.

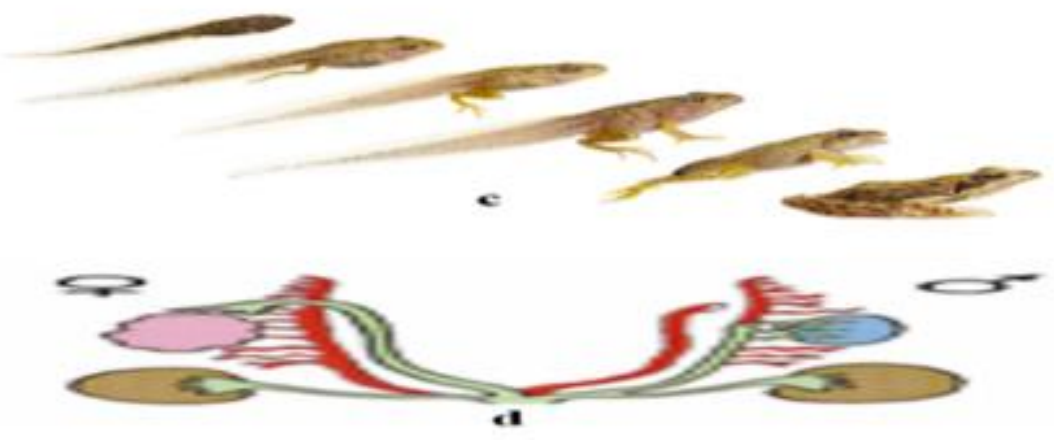

Figure 7 (a) Controlling cell numbers during neurogenesis; up to 80\% of neurons die in some ganglia. (b) Matching number of cells; both neurons and oligodendrocytes are produced in excess, and up to 50\% or more die apparently to adjust their numbers to the number of target cells they innervate. (c) Tadpole metamorphosis; tadpole $\rightarrow$ tadpole with hind limbs $\rightarrow$ tadpole with four limbs $\rightarrow$ froglet with tail reabsorbed into body $\rightarrow$ adult frog [ http://www.timhuntphotography.co.uk/]. (d) Deleting unwanted structures that are in one sex but needed in the other sex e.g. Mullerian duct important for female is eliminated in males by apoptosis [46, 52].

In contrast, the Wolffian duct develops into the vas deferens, epididymis, and seminal vesicle in males, but it is not required in females and therefore removed by apoptosis (Figure 7d). Additionally, developmentally-regulated apoptosis occurs in the bud during digits (fingers and toes) formation in the vertebrate fetus (Figure 8a and 8b) [23, 53-54]. Failure of proper apoptosis results in malfunctions such as syndactyly and polydactyly (Figure 8c and 8d).
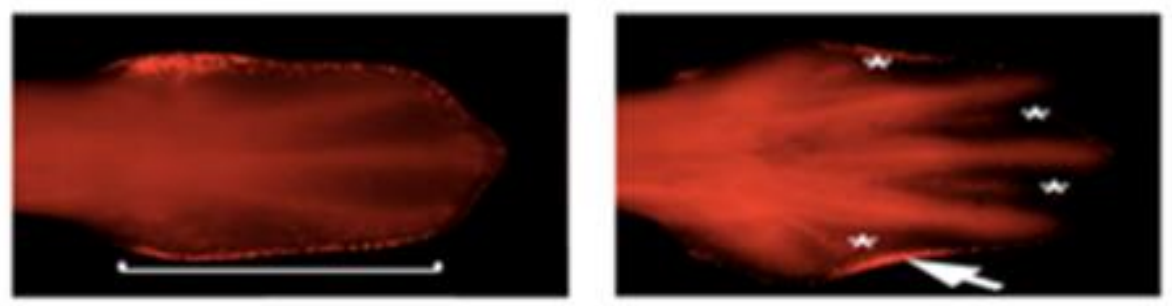

Developing mouse paw,

a. Embryonic day 12.5

b. Embryonic day 13.5

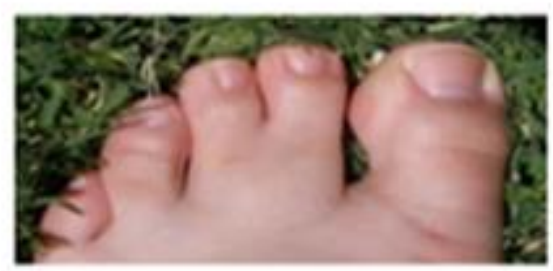

C

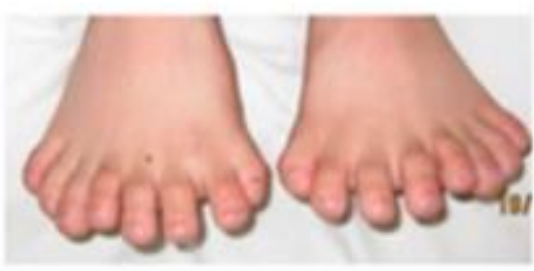

d

Figure 8 (a) and (b) Development of mouse limbs and sequential passage of time of digits. Red dots show cells undergoing apoptosis [59]. Consequences of inappropriate apoptosis in developing human embryo. (c) Deficient 
apoptosis causes fusion of digits (syndactyly) leading to less digits (oligodactyly). (d) Excessive apoptosis results in extra digits (Polydactyly) [23].

Another striking example for the function of apoptosis in preserving cell quality control in the body is found in the development of the vertebrate immune system (Figure 9). Apoptosis primarily evolved as host defence mechanism, in response to pathogens, eliciting inflammation with certain molecular, cellular, biochemical, morphological and physiological changes $[15,55]$. The proper functioning of mature mammalian immune system depends on the controlled destruction of many immune cell-types. Autoreactive T and B cells are first produced in millions every day. They are tested to see if they develop self-reactive receptors and react against any of the body's own "self" components. If the process of elimination of white blood cells that would produce an immune response to the body's own cells fails (Figure $9 \mathrm{a}$ and $9 \mathrm{~b}$ ), self-reactive cells may be released into the body. In this situation, the cells can attack tissues and cause autoimmune conditions.

When a pathogen is detected, the immune system turns off its response to recognize the pathogen [52, 55-56]. The immune cells proliferate extensively, producing a huge increase in numbers with the purpose of destroying the pathogen (Figure 9c, Right). The immune cells possess intrinsic surveillance mechanisms to detect and get rid of harmful or damaged cells. Body cells infected with certain pathogens, e. g some viruses, present fragments of antigenic proteins on surface receptor proteins on their cell membranes. Once the pathogen is cleared from the body, the large numbers of pathogen-specific immune cells are no longer needed and must be removed by apoptosis to maintain homeostasis in the immune system.

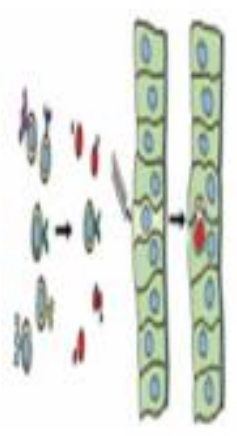

a

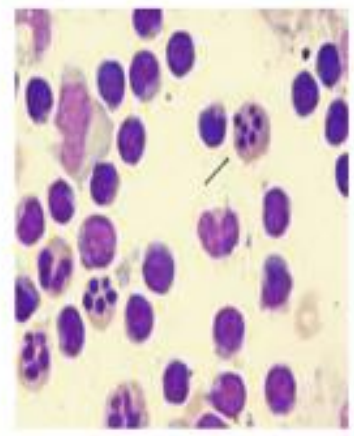

b

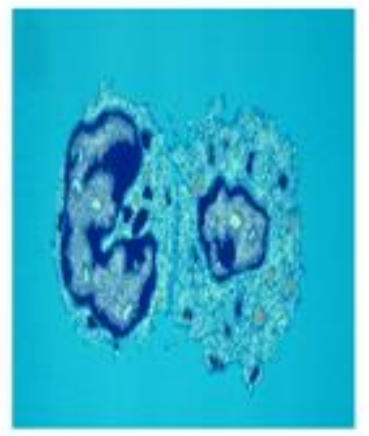

C

Figure 9 (a) Apoptosis serves quality-control function in immune system as a defense mechanism to get rid of nonfunctional, harmful, abnormal, or misplaced cells [46]. (b) Apoptosis of surplus neutrophils. Right: (c) In the absence of inhibitory signals, activating cytotoxic killer cells receptor ligate with molecules on the target cell infected with virus on right. This results in target cell lysis. Source: britannica.com.

\subsection{Development of cancer}

Cell death is necessary to prevent cells from surviving in environments where they should not be present. Abnormality in the apoptotic process may result in immoral cells, which is one of the main features of malignant cells [57]. Thus, cancer cells escape apoptosis via initiating and implicating faulty apoptosis, etc. Dysregulation of apoptosis has emerged as a new concept to explain important features in the development of several diseases that are that are characterized by unbalance between cell proliferation and cell death [50]. Cancer results from hyperplasia due to deficient apoptosis. Conversely, degenerative diseases may be caused by excessive apoptosis leading to tissue atrophy [5, 57]. In cancer, the apoptotic pathway is typically inhibited through different means including overexpression of anti-apoptotic proteins and low-expression of pro-apoptotic proteins [33]. Understanding of malfunctions in apoptosis may help in finding explanation of the pathogenic conditions. This will contribute to overcoming resistance to anti-cancer drugs by designing molecules which can target specific apoptotic genes or pathways and ultimately reverting apoptotic abnormalities or inducing apoptosis in malignant cells [32]. In general, the mechanisms by which errors may occur at any point along apoptotic pathways can be broadly dividend into: 1) disrupted balance of pro-apoptotic and antiapoptotic proteins, 2) reduced caspase function and 3) impaired death receptor signaling.

\subsection{Disrupted balance of pro-apoptotic and anti-apoptotic proteins}

Pro-and anti-apoptotic proteins play an important role in regulating an exquisite balance not only between health and disease but also between life and death. 


\subsection{The Bcl-2 family of proteins}

A large number of Bcl-2 proteins have been identified [11, 58-59]. Based upon their sequence, the Bcl-2 family (Table 2) is classified into: a) anti-apoptotic proteins, Bcl-2, Bcl-xL, Mcl-1, Bcl-w, A1/Bfl-1, and Bcl-B/Bcl2L10 possess all the four domains (BH1-4). b) pro-apoptotic proteins with the BH domains 1, 2 and 3. Some examples of this group include Bax, Bak, and Bok/Mtd. The third group (c) is the BH3-only proteins which include Bid, Bim, Puma, Noxa, Bad, Bmf, Hrk, and Bik. The Bcl-2 members can be translocated to other locations including ER, Golgi apparatus (GA), Nucleus, OMM or NOM. Other Bcl-2 related proteins are also found in peroxisomes [58, 60]. Bcl-2 proteins; particularly Bax and Bak are directly responsible for the loss of MOM integrity and regulate MOM permeabilization (MOMP) indirectly (Figure 10 ) leading to irreversible release of intermembrane space enzyme cytochrome $C$ [11, 14, 58-59]. They also participate in major cellular processes including calcium homeostasis, cell cycle control and cell migration. Under stress conditions such as DNA damage, deprivation of GFs, the BH3-only proteins are activated act as pro-apoptotic by initiating of apoptosis [39]. In the nucleus, it was found that a fraction of the BH3-only protein plays a role in the DNA damage response [61]. Because of its potent anti-tumorigenic activity many BH3 mimetics e.g. ABT-737, ABT-263, and obatoclax have been developed and tested clinically [62]. However, the possible localization at the level of these diverse internal membranes is an emerging concept and the mechanisms governing $\mathrm{Bcl}-2$ translocation as well as their actual biological function remain poorly understood [59].

Table 2 Representatives of the Bcl-2 family proteins and their subcellular locations. Adapted from [58].

\begin{tabular}{|c|c|c|c|c|c|c|c|c|c|c|}
\hline \multirow[t]{2}{*}{ Protein } & \multicolumn{10}{|c|}{ Location } \\
\hline & ER & $\mathrm{NE}$ & TGN & C & MOM & MM & MIM & CS & PM & $\mathrm{N}$ \\
\hline Bcl-2 & $X X$ & $X X$ & & & $\mathrm{XX}$ & & & & & \\
\hline \multicolumn{11}{|l|}{ Bcl-xL } \\
\hline & & & & & XX & & & & & \\
\hline Mcl-1 & & & & & $X X$ & & & & & \\
\hline & & & & & XX & & & & & \\
\hline \multirow[t]{2}{*}{ Bax } & & & & XX & & & & & & \\
\hline & & & & & XX & & & & & \\
\hline Bak & & & & & $\mathrm{XX}$ & & & & & \\
\hline \multicolumn{11}{|l|}{ Bok } \\
\hline \multicolumn{11}{|l|}{ Bid } \\
\hline Puma & & & & & $x X$ & & & & & \\
\hline \multirow[t]{2}{*}{ Noxa } & & & & & $X X$ & & & & & \\
\hline & & & & & $\mathrm{XX}$ & & & & & \\
\hline $\mathrm{Bad}$ & & & & $X X$ & & & & & & \\
\hline Bil & $\mathrm{XX}$ & & & & & & & & & \\
\hline Beclin-1 & $\mathrm{XX}$ & & & & & & & & & \\
\hline Spike & & & & $X X$ & & & & & & \\
\hline Bap31 & XX & & & & & & & & & \\
\hline $\mathrm{Bfk}$ & & & & $\mathrm{XX}$ & & & & & & \\
\hline Bcl-Rambo & & & & & $X X$ & & & & & \\
\hline
\end{tabular}

C: Cytosol; CS: Cytoskeleton; ER: Endoplasmic Reticulum; NE: Nuclear Envelope; MOM: Mitochondrial Outer Membrane; MIM: Mitochondrial Inner Membrane; MM: Mitochondrial Matrix; PM: Plasma Membrane; TGN: trans Golgi network. Black: normal conditions; Grey: apoptotic conditions. XX: Predominant location.

Disturbance of the balance of anti-apoptotic and pro-apoptotic members of the Bcl-2 family results in dysregulated apoptosis in the affected cells. This can be due to an overexpression of one or more anti-apoptotic proteins or low expression of one or more pro-apoptotic proteins or a combination of both. For example, the overexpression of Bcl-2 protected cancerous cells of different origin, while overexpression of Bcl-xL confers a multi-drug resistance phenotype 
in tumor cells and prevent them from undergoing apoptosis [14, 17, 39, 58, 63-64]. The advent of BH3 mimetic drugs represents a notable advance in cancer treatment (Figure 10).

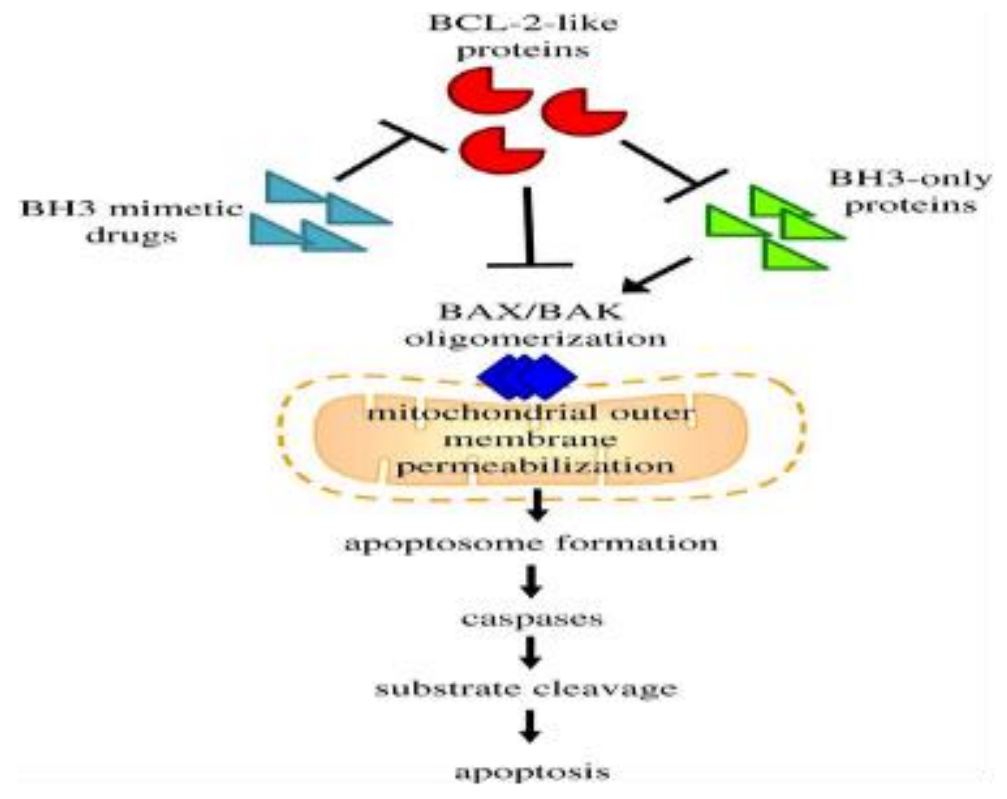

Figure 10 Role of Bcl-2 family proteins in the life-death decision point within the common pathway of apoptosis. The interaction between pro-survival and pro-apoptotic BCL-2 proteins sets a threshold for activation of apoptosis. The BH3-only proteins control this process by direct BAX/BAK activation or by repressing the anti-apoptotic Bcl-2 family members. Drugs mimicking the action of BH3-only proteins indirectly lead to BAX/BAK activation [14, 39].

\section{6. p53}

The p53 is an oncosuppressor protein, which transcriptionally control the expression of a number of genes that in turn regulate many functions. It responds to DNA damage, oncogene triggering, oxidative, and other cell stresses. Arrests of cell growth between G1 $\rightarrow \mathrm{S}$ (the G1 checkpoint) is mediated by p53 activation (Figure 11) [65-67]. This delay allows for DNA repair machineries to restore genome stability. Alteration of the p53 pathway also contributes to apoptosis evasion. If the damage is too extensive then p53 induces gene activation leading to apoptosis, thus preventing proliferation of cell with defective genomes [65]. Inactivation, elimination, and abnormal expression of the p53 gene play important roles in carcinogenesis. About $80 \%$ of human tumors are caused by dysfunctional p53 signaling and $50 \%$ by 553 gene mutation [66-68].

It was proved that early p53-induced apoptotic cells can be rescued from the apoptotic program if the apoptotic stimulus is removed [69]. This suggested that DNA repair is initiated early in the p53-induced apoptotic process and that this DNA repair may be involved in reversing the cell death pathway under certain circumstances. An interesting developing field in p53 biology is the studies related to its cytoplasmic function(s) [70]. The cytoplasmic p53 acts in a transcriptional-independent manner controlling important cell homeostasis processes. In cancer research, the p53 modifiers could be promising candidates to elucidate apoptosis or other important transcriptional-independent activities needed to develop new therapeutic approaches. Bcl-2 has been demonstrated to inhibit p53-mediated apoptosis but cannot inhibit p53 translocation toward nucleolus or p53-mediated growth arrest. The ability of p53 to control many transcriptional programs and cellular functions possibly explains its potent tumor suppressor activity [71-72]. Abnormal expression of p53 downregulates Bax/Noxa/Puma expression and upregulates Bcl-2. The possible role of Bcl-2 is to block the activation of the apoptotic signals to their target molecules [73]. The upregulation of Bcl-2 prevents cytochrome $\mathrm{C}$ release from the mitochondria, inhibiting p53-mediated apoptosis. The downregulation of Bax prevents the formation of mitochondrial apoptosis-induced channel on the OMM, reducing the pro-apoptotic effect [74]. Cytological and biochemical studies in the context of living organisms are likely to reveal yet additional functions of p53 in responding to genome instability. The future success of p53-targeted therapies needs deep understanding of the detailed mechanisms of regulation of p53 apoptosis and cell-cycle functions. This will enable development of highly effective and specific strategies for cancer prevention including CRISPR/Cas9 based genome editing [75]. 


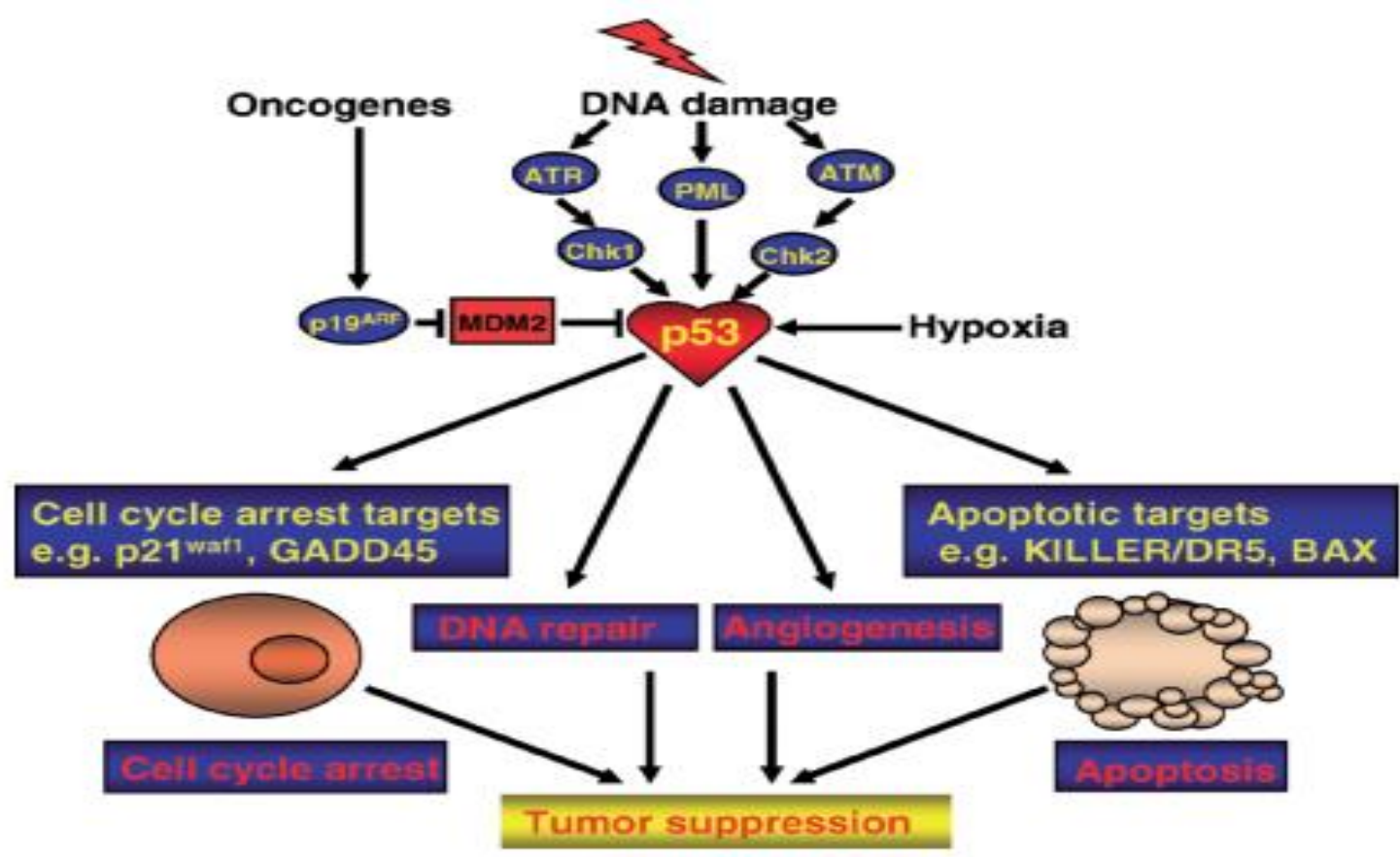

Figure 11 Interaction between extrinsic stressors and p53- dependent signalling dictates cell fate. In general, these signals stabilize p53 leading to an increased in cellular levels of p53. The role by, which include DNA repair, apoptosis, and senescence. The functional p53 exerts its protective effect by promoting different mechanisms, which include cell cycle arrest (senescence) or induction of apoptosis, thereby suppressing tumour formation [65].

\section{Inhibitor of apoptosis proteins (IAPs)}

The inhibitors of apoptosis (IAPs) represents an important group of structurally and functionally related anti-apoptotic proteins. Several IAPs have been identified [12], such as neuronal apoptosis inhibitory protein (NAIP) or (baculovirus inhibitor of apoptosis repeat-containing protein 1; BIRC1), cellular IAP1 and IAP2 (cIAP1 and cIAP2 c-IAP1 or BIRC2 or BIRC3, respectively), X-linked IAP (XIAP, BIRC4), Survivin (BIRC5), baculoviral IAP repeat (BIR)-containing ubiquitin conjugating enzyme (BRUCE; Apollon), Livin/ML-IAP (BIRC7) and IAP-like protein 2 (BIRC8) [12, 37]. The defining characteristic of IAPs is the existence of the BIR domain. IAPs are endogenous inhibitors of caspases (Figure 12) and they can inhibit caspase activity by binding their conserved BIR domains to the active sites of caspases, by promoting destruction of active caspases or by keeping them away from their substrates [11].

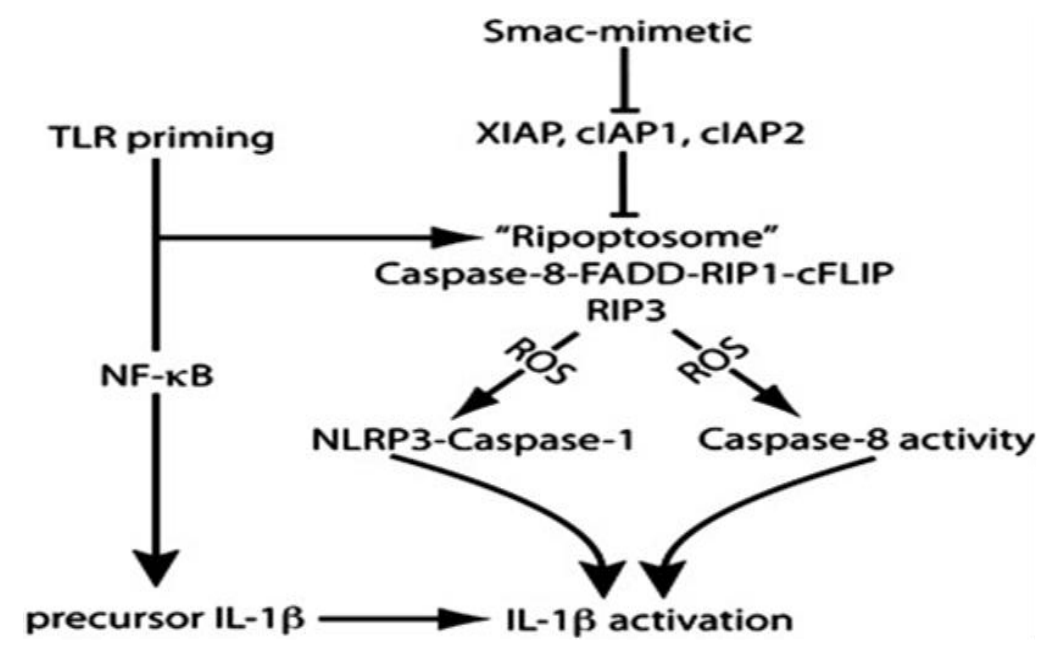

Figure 12 Inhibitor of apoptosis proteins (IAPs) 
Figure 12 Inhibitor of apoptosis proteins (IAPs), such second mitochondrial activator of caspases (Smac) bind to XIAP, cIAP1, and cIAP2 and antagonize the caspase binding function of XIAP. The ripoptosome contains receptor-interacting protein-1/Receptor-Interacting Protein-3 (RIP1). Cellular FLICE-like inhibitory protein (cFLIP) inhibits FADD-induced caspase-8 homodimerization in complex II, blocking apoptosis. ROS can mediate apoptosis by changing the expression of different pro-apoptotic proteins such as caspases or anti-apoptotic proteins such as B cell lymphoma-2 (Bcl-2) and cFLIP. Toll-like receptor (TLR) priming potentiate IL-1 $\beta$ mRNA induction. The cascade reactions end with activation of

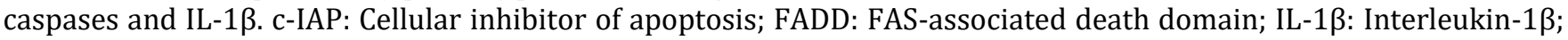
Nuclear factor-kappaB (NF- kB), NLR: Nod-like receptor; NLRP3: NOD-like receptor protein 3; ROS: Reactive oxygen species [76].

The IAPs have an important role in modulation of various cellular activities, including cell death, cell cycle, and cell differentiation as well as immune responses [77-78]. The list of IAPs cellular roles continues to expand as studies implicate them in a growing number of signaling cascades [12]. The anti-apoptotic effect of IAPs promotes uncontrolled cell division, and for this reason upregulation of IAPs is associated with numerous types of cancer as a mechanism of resistance to cell death and chemotherapy [76-79]. During apoptosis, the IAP-mediated caspase inhibition is eliminated by a mitochondrial protein named Smac (second mitochondria-derived activator of caspases) or DIABLO (direct IAPbinding protein with low pI) [80]. Smac is an endogenous inhibitor of IAPs, and several small molecule mimetics of smac have been developed to bind and antagonize IAPs (Smac /DIABLO) (Figure 12) in cancer cells and restore sensitivity to apoptotic stimuli $[78,81]$. The abnormal expression of the IAPs was responsible for resistance to chemotherapy [73, 82-84]. Thus, targeting IAPs seems to be a promising approach for improved cancer therapy. Compared to cytotoxic cancer preventive molecules, IAPs inhibitors are less toxic to normal cells, and preserve favorable safety profiles through clinical studies [82].

\subsection{Reduced caspase activity}

Since caspases are key players in apoptosis, it is reasonable to think that low levels of caspases or impairment in their function may result in decreased rate in apoptosis and consequently incidence of carcinogenesis [85]. Inappropriate activation of caspases and dysregulation of the cell death and inflammatory pathways they control has profound consequences for human health [86]. Decreased caspase-2 expression or activity was shown to affect both p53 stabilization and the expression of p53-inducible genes in response to DNA damage [85]. Downregulation of caspase-9 was in stage II colorectal cancer patients and correlates with poor clinical outcome [87]. About 75\% of the breast cancer samples lacked caspase-3 transcripts and caspase-3 protein expression [88]. In the latter study, the levels of expression of caspases-3 mRNA were either undetectable (breast and cervical) or substantially low (ovarian). Another study [89] suggested that pancreatic cancer may attributed to disturbances in the initiation of cancer cell apoptosis through a decrease in the expression of caspase-8, which may cause abnormal regulation in the activation of effector caspase-3. This study [89] also suggested that the loss of caspases-3 expression and function could contribute to breast cancer cell survival. In some cases, more than one caspase (capase-8 and -10 , for example) can be downregulated, participating in tumor development.

\subsection{Impaired death receptor signaling}

It is well documented that DRs and ligands are crucial mediator of cell fate. CD95 (Fas/APO-1), one of the most widely studied death receptor signaling, has long been viewed as trigger which activates a signaling cascade, mediates apoptosis and maintains immune homeostasis [90]. However, it was demonstrated that DLs can also bind to decoy DRs that do not have a DD and the latter fail to form signaling complexes and initiate the signaling cascade [38].

Different aberrations in the death signaling pathways; decreased expressions of both DR and DL genes, or dysfunction of the function of these receptor, have been reported to allow the evasion of the extrinsic apoptotic pathway. [37, 91] All mentioned mechanisms perturb the transmission of death signaling downstream and hence resulting in impaired signaling and consequently reducing apoptotic rate [92]. Impairments in leukemia and Tymphoma DR signaling lead to what is known as primary Chimeric antigen receptor (CAR) CAR T19 resistance [91, 93]. These major side effects have precluded the systemic use of CD95L cancer therapy, revealing a novel mechanism for acquired drug resistance. Therefore, it becomes evident that understanding of cell death signaling pathways is relevant to developing more effective cancer therapeutics.

\section{Conclusion}

Cell death in living systems occurs either by apoptosis or by non-apoptotic mechanisms. Apoptosis is an essential process for the growth, development and maintenance of healthy tissues. A lack of apoptotic cell death is thought to be a key driver of oncogenesis. If damage is too extensive (pathologic), cells have no choice but to undergo the genetically 
uncontrolled necrotic form of death. If on the other hand cellular damage is more subtle (physiologic), death occurs through the genetically controlled apoptosis. Apoptosis a double-edged sword, can be the cause of the problem and the solution of it. The precise mechanisms of ER signaling pathways in cell death have not been entirely clarified. The involvement of micro RNAs in cell survival and death signaling is likely to open up new avenues of research in this field. Unravelling of how different stress sensors such as ROS contribute to switching from survival to death may help in clarifying these unresolved issues and provide fundamental information, guidance and new strategies for the development of better therapeutics to treat some human diseases. All studies reported in this review dealt with research conducted on animal cells. It is clear that research of plant cell death is relatively unexplored and requires further investigations.

\section{References}

[1] Galluzzi L, Vitale I, Aaronson SA, Abrams JM, Adam D, Agostinis P, et al. Molecular mechanisms of cell death: recommendations of the nomenclature committee on cell death 2018. Cell Death Differ. Mar 2018; 5: 486-541.

[2] Chen Q, Kang J, Fu C. The independence of and associations among apoptosis, autophagy, and necrosis. Sig Transduct Target Ther. 01 Jul 2018; 3: 18.

[3] Noguchi M, Hirata N, Edamura T, Ishigaki S, Suizu F. Intersection of apoptosis and autophagy cell death pathways. Austin J Mol Cell Biol. 22 May 2015; 2(1): 10-04.

[4] Lockshin RA, Zakeri Z. Apoptosis, autophagy, and more. Int J Biochem Cell Biol. Dec 2004; 36(12): 2405-19.

[5] Elmore S. Apoptosis: A Review of programmed cell death. Toxicol Pathol. 01 Jun 2007; 35(4): $495-516$.

[6] Ma Y, Han F, Min J, Lin W. Energy metabolism as a regulator of ferroptosis. Cell Cycle. 28 Oct 2020.

[7] Gao M, Yi J, Zhu J, Minikes AM, Monian P, Thompson CB, et al. Role of mitochondria in ferroptosis. Mol Cell. 17 Jan 2019; 73(2): 354-63.

[8] Lee H, Zandkarimi F, Zhang Y, Meena JK, Kim J, Zhuang L, et al. Energy-stress-mediated AMPK activation inhibits ferroptosis. Nat Cell Biol. 28 Jun 2020; 22(2): 225-34.

[9] Darzynkiewicz Z, Juan G, Li X, Gorczyca W, Murakami T, Traganos F. Cytometry in cell necrobiology: Analysis of apoptosis and accidental cell death (necrosis). Cytometry. 01 Jan 1997; 27: 1-20.

[10] Zeiss CJ. The apoptosis-necrosis continuum: insights from genetically altered mice. Vet Pathol. Sep 2003; 40: 48195.

[11] Indran IR, Tufo G, Pervaiz S, Brenner C. Recent advances in apoptosis, mitochondria and drug resistance in cancer cells. Biochem Biophys Acta Bioenerg. Jun 2011; 1807(6): 735-45.

[12] Kocab AJ, Duckett CS. Inhibitor of apoptosis proteins as intracellular signaling intermediates. FEBS J. Jan 2016; 283: 221-31.

[13] Atkin-Smith GK, Poon IH. Disassembly of the dying: Mechanisms and functions. Trends Cell Biol. Feb 2017; 27(2): 151-62.

[14] Campbell KJ, Tait SG. Targeting BCL-2 regulated apoptosis in cancer. Open Biol. May 2018; 180002.

[15] Kashyap B, Reddy PS. Physiologic to pathologic cellular and molecular levels of elusive cell death programs and their manipulative action. Clin Oncol. 03 Dec 2019; 4: 16-74.

[16] D'Arcy MS. Cell death: a review of the major forms of apoptosis, necrosis and autophagy. Cell Biol Int. Jun 2019; 43: 582-92.

[17] D'Aguanno S, Del Bufalo D. Inhibition of anti-apoptotic Bcl-2 proteins in preclinical and clinical studies: Current overview in cancer. Cells. 21 May 2020; 9: 1287.

[18] Kerr JR, Wyllie AH, Currie AR. Apoptosis: a basic biological phenomenon with wide-ranging implications in tissue kinetics. Br J Cancer. Aug 1972; 26: 239-57.

[19] Poon IK, Lucas CD, Rossi AG, Ravichandran KS. Apoptotic cell clearance: basic biology and therapeutic potential. Nat Rev Immunol. Mar 2014; 14(3): 166-80.

[20] Balvan J, Krizova A, Gumulec J, Raudenska M, Sladek Z, Sedlackova M, et al. Multimodal holographic microscopy: Distinction between apoptosis and oncosis. PLoS ONE. May 2015; 10(3): e0121674.

[21] Lanka P. Difference between apoptosis and necrosis. Pediaa.Com. May 2017. 
[22] Archana M, Bastian, Yogesh T L, Kumaraswamy K L. Various methods available for detection of apoptotic cells- A review. Indian J Cancer. Jul-Sep 2013; 50: 274-83.

[23] Kendall T. Apoptosis. College of Medicine and Veterinary Medicine. The University of Edinburgh. 2020.

[24] Doonan F, Cotter TG. Morphological assessment of apoptosis. Methods. Mar 2008; 4(3): 200-4.

[25] Pietkiewicz S, Schmidt JH, Inna N. Lavrik IN. Quantification of apoptosis and necroptosis at the single cell level by a combination of Imaging Flow Cytometry with classical Annexin V/propidium iodide staining. J Immunol Methods. Aug 2015; 423: 99-103.

[26] Makarov R, Geserick P, Feoktistova M, Leverkus M. Cell death in the skin: how to study its quality and quantity? Methods Mol Biol. Aug 2013 ; 961: 201-18.

[27] Hacker G. The morphology of apoptosis. Cell Tissue Res. Jul 2000; 301: 5-17.

[28] Khalil AM, Alemam IF, Al-Qaoud KM. Association between mobile phone using and DNA damage of epithelial cells of the oral mucosa. J Biotechnol Biomed. 29 May 2020; 3(2): 050-066.

[29] Julien O, Wells J. Caspases and their substrates. Cell Death Differ. 12 May 2017; 24: 1380-89.

[30] McComb S, Chan PK, Guinot A, Hartmannsdottir H, Jenni S, Dobay MP, et al. Efficient apoptosis requires feedback amplification of upstream apoptotic signals by effector caspase-3 or -7. Sci Adv. 31 Jul 2019; 5: eaau9433.

[31] Balakireva AV, Zamyatnin A Jr. Cutting out the gaps between proteases and programmed cell death. Front. Plant Sci. 2019 Jun 04;10:704.

[32] Belkacemi L. Exploiting the extrinsic and the intrinsic apoptotic pathways for cancer therapeutics. J Cancer Cure. 2018; 1(1): 1004.

[33] Pfeffer CM, Singh AK. Apoptosis: A Target for anticancer therapy. Int J Mol Sci. 02 Feb 2018; $19: 448$.

[34] Szegezdi E, Fitzgerald U, Samali. Caspase-12 and ER stress mediated apoptosis: the story so far. Ann NY Acad Sci. Dec 2003; 1010: 186-94.

[35] O'Brien MA, Kirby R: Apoptosis: a review of pro-apoptotic and anti-apoptotic pathways and dysregulation in disease. J Vet Emerg Crit Care. Dec 2008; 18(6): 572-85.

[36] Portt L, Norman G, Clapp C, Greenwood M, Greenwood MT. Anti-apoptosis and cell survival: A review. Biochim Biophys Acta. Jan 2011; 1813: 238-59.

[37] Choo Z, Loh AP, Chen ZX. Destined to die: Apoptosis and pediatric cancers. Cancers. 23 Oct 2019; 11(11): 1623.

[38] Walczak H. Death receptor-ligand systems in cancer, cell death, and inflammation. Cold Spring Harb Perspect Biol. 01 May 2013; 5(5): a008698.

[39] Adams JM, Cory S. The BCL-2 arbiters of apoptosis and their growing role as cancer targets. Cell Death Differ. Jan 2018; 25: 27-36.

[40] Deming P, Kurokawa M. Dismantling the apoptotic cell by caspases. eLS - Wiley Online Library. 20 Mar 2017.

[41] Stewart CL, Roux KJ, Burke B. Blurring the boundary: The nuclear envelope extends its reach. Science. 30 Nov 2007; 318(5855): 1408-12.

[42] Jiang L, Poon IH. Methods for monitoring the progression of cell death, cell disassembly and cell clearance. Apoptosis. 25 Jan 2019; 24: 208-20.

[43] Hoeppner DJ, Hengartner MO, Schnabel R. Engulfment genes cooperate with ced-3 to promote cell death in Caenorhabditis elegans. Nature. 12 Jul 2001; 412: 202-6.

[44] Reddien PW, Cameron S, Horvitz HR. Phagocytosis promotes programmed cell death in C. elegans. Nature. 12 Jul 2001; 412: 198-202.

[45] Horvitz HR. Genetic control of programmed cell death in the nematode Caenorhabditis elegans. Cancer Res. 01 Apr 1999; 59: 1701-06.

[46] Jacobson MD, McCarthy N, editors. Apoptosis: The Molecular Biology of Programmed Cell Death. Frontiers in Molecular Biology, Volume 40. Oxford and New York: Oxford University Press. 2002.

[47] Lamkanfi M, Festjens N, Declercq W, Vanden Berghe T, Vandenabeele P. Caspases in cell survival, proliferation and differentiation. Cell Death Differ. Jan 2007; 14(1): 44-55. 
[48] Ryu JR, Hong CJ, Kim, JY, Kim E-K, Sun W, Yu S-W. Control of adult neurogenesis by programmed cell death in the mammalian brain. Mol Brain. 21 Apr 2016; 9(43).

[49] Hollville E, Romero SE, Deshmukh M. Apoptotic cell death regulation in neurons. FEBS J. 23 Jun 2019; 286: 327679.

[50] Fricker M, Tolkovsky AM, Borutaite V, Coleman M, Brown GC. Neuronal cell death. Physiol Rev. 01 Apr 2018; 98(2): 13-80.

[51] Curtin JF, Cotter TG. Apoptosis: Historical perspectives. Essays Biochem. 2003; 39: 1-10.

[52] Kurd NS, Lutes LK, Yoon J, Chan SW, Dzhagalov IL, Hoover AR, et al. A role for phagocytosis in inducing cell death during thymocyte negative selection. Elife. 23 Dec 2019; 8: e48097.

[53] Zeller R, Lopez-Rios J, Zuniga A. Vertebrate limb bud development: moving towards integrative analysis of organogenesis. Nat Rev Genet. Dec 2009; 10: 845-58.

[54] Farin HF, Lüdtke TH-W, Schmidt MK, Placzko S, Schuster-Gossler K, Petry M, et al. Tbx2 terminates Shh/Fgf signaling in the developing mouse limb bud by direct repression of gremlin1. PLoS Genet. 25 Apr 2013; 9(4): e1003467.

[55] Yang Y, Jiang G, Zhang P, Fan J. Programmed cell death and its role in inflammation. Mil Med Res. 19 May 2015; 2: 12.

[56] Labbé K, Saleh M. Cell death in the host response to infection. Cell Death Differ. Sep 2008; 15(9): 1339-49.

[57] Junaid M, Akter Y, Afrose SS., Tania M, Khan MA. Apoptotic cell death: Important cellular process as chemotherapeutic target. In: Tuli HS, editors. Drug Targets in Cellular Processes of Cancer: From Nonclinical to Preclinical Models. Springer: Singapore. 2020.

[58] Kale J, Osterlund E, Andrews D. BCL-2 family proteins: changing partners in the dance towards death. Cell Death Differ. Jan 2018; 25: 65-80.

[59] Naumova N, Šachl R. Regulation of cell death by mitochondrial transport systems of calcium and Bcl-2 proteins. Membranes. 10 Oct 2020; 10(10): 299.

[60] Popgeorgiev N, Jabbour L, Gillet G. Subcellular localization and dynamics of the Bcl-2 family of proteins. Front Cell Dev Biol. 13 Feb 2018; 6: 13.

[61] Zinkel SS, Hurov KE, Ong C, Abtahi FM, Gross A, Korsmeyer SJ. A role for proapoptotic BID in the DNA-damage response. Cell. 26 Aug 2005; 122: 579-91.

[62] Shukla S, Saxena S, Singh BK, Kakkar P. BH3-only protein BIM: An emerging target in chemotherapy. Eur J Cell Biol. Dec 2017; 96(8): 728-38.

[63] Sharifi S, Barar J, Hejazi MS, Samadi N. Roles of the Bcl-2/Bax ratio, caspase-8 and 9 in resistance of breast cancer cells to paclitaxel. Asian Pac J Cancer Prev. 2014; 15: 8617-22.

[64] Liu Z, Wild C, Ding Y, Ye N, Chen H, Wold EA, Zhou J. BH4 domain of Bcl-2 as a novel target for cancer therapy. Drug Discov Today. 26 Nov 2016; 21(6): 989-96.

[65] Wang S, El-Deiry WS. P53, cell cycle arrest and apoptosis. In: Hainaut P, Wiman KG, editors. 25 Years of p53 Research, Chapter 6. Springer. 2007; 141-63.

[66] Ozaki T, Nakagawara A. Role of p53 in cell death and human cancers. Cancers. Mar 2011; 3(1): 994-1013.

[67] Aubrey BJ, Kelly GL, Janic A, Herold MJ, Strasser A. How does p53 induce apoptosis and how does this relate to p53-mediated tumour suppression? Cell Death Differ. Jan 2018; 25: 104-13.

[68] Amelio I, Melino G. Context is everything: extrinsic signalling and gain-of-function p53 mutants. Cell Death Discov. Mar 2020; 6: 16.

[69] Geske FJ, Lieberman R, Strange R, Gerschenson LE. Early stages of p53-induced apoptosis are reversible. Cell Death Differ. 17 Apr 2001; 8(2): 182-91.

[70] Della-Fazia MA, Castelli M, Piobbico D, Pieroni S, Servillo G. The Ins and Outs of HOPS/TMUB1 in biology and pathology. FEBS J. 29 Aug 2020.

[71] Mello SS, Attardi LD. Deciphering p53 signaling in tumor suppression. Curr Opin Cell Biol. Apr 2018; 51: 65-72. 
[72] Pitolli C, Wang Y, Candi E, Shi Y, Melino G, Amelio I. p53-mediated tumor suppression: DNA-damage response and alternative mechanisms. Cancers. 09 Dec 2019; 11(12): 983.

[73] Chen L, Zeng Y, Zhou S-F. Role of apoptosis in cancer resistance to chemotherapy, In: Tutar Y, editors. Current Understanding of Apoptosis - Programmed Cell Death, IntechOpen. 29 Aug 2018; 125-136.

[74] Yang HJ, Wang M, Wang L, Cheng BF, Lin XY, Feng ZW. NF-кB regulates caspase-4 expression and sensitizes neuroblastoma cells to Fas-induced apoptosis. PLoS One. 19 Feb 2015; 10: e0117953.

[75] Zhu G, Pan C, Bei J-X, Li B, Liang C, Xu Y, et al. Mutant p53 in cancer progression and targeted therapies. Front Oncol. 06 Nov 2020.

[76] Vince JE, Wong WW-L, Gentle I, Lawlor KE, Allam R, O’Reilly L, et al. Inhibitor of apoptosis proteins limit RIP3 kinase-dependent interleukin-1 activation. Immunity. 24 Feb 2012; 36(2): 215-27.

[77] Liang J, Zhao W, Tong P, Li P, Zhao Y, Li H, et al. Comprehensive molecular characterization of inhibitors of apoptosis proteins (IAPs) for therapeutic targeting in cancer. BMC Med Genomics. 21 Jan 2020; $13: 7$.

[78] Michie J, Kearney CJ, Hawkins ED, Silke J, Oliaro J. The immuno-modulatory effects of inhibitor of apoptosis protein antagonists in cancer immunotherapy. Cells. 14 Jan 2020; 9: 207.

[79] Cong H, Xu L, Wu Y, Qu Z, Bian T, Zhang W, et al. Inhibitor of apoptosis protein (IAP) antagonists in anticancer agent discovery: Current status and perspectives. J Med Chem. 27 Jun 2019; 62(12): 5750-72.

[80] Chai J, Du C, Wu JW, Kyin S, Wang X, Shi Y. Structural and biochemical basis of apoptotic activation by Smac/DIABLO. Nature. 24 Aug 2000; 406(6798): 855-62.

[81] Condon SM, Mitsuuchi Y, Deng Y, LaPorte MG, Rippin SR, Haimowitz T, et al. Birinapant, a smac-mimetic with improved tolerability for the treatment of solid tumors and hematological malignancies. J Med Chem. 08 May 2014; 57(9): 3666-77.

[82] Finlay D, Teriete P, Vamos M, NDP C, Vuori K. Inducing death in tumor cells: roles of the inhibitor of apoptosis proteins. F1000Res. 27 Apr 2017; 6: 587.

[83] Garg H, Suri P, Gupta JC, Talwar GP, Dubey S. Survivin: a unique target for tumor therapy. Cancer Cell Int. 23 Jun 2016; 16: 49.

[84] Carneiro BA, El-Deiry WS. Targeting apoptosis in cancer therapy. Nat Rev Clin Oncol. Jul 2020; 17 : 395-417.

[85] Olsson M, Zhivotovsky B. Caspases and cancer. Cell Death Differ. 01 Apr 2011; 18(9): 1441-49.

[86] McIlwain DR, Berger T, Mak TW. Caspase functions in cell death and disease. Cold Spring Harb Perspect Biol. Apr 2015; 7: a026716.

[87] Shen X-G, Wang C, Li Y, Wang L, Zhou B, Xu B, et al. Downregulation of caspase-9 is a frequent event in patients with stage II colorectal cancer and correlates with poor clinical outcome. Colorectal Dis. Dec 2010; 12(12): 121318.

[88] Devarajan E, Sahin AA, Chen JS, Krishnamurthy RR, Aggarwal N, Brun A-M, et al. Down-regulation of caspase 3 in breast cancer: a possible mechanism for chemoresistance. Oncogene. 12 Dec 2002; 21: 8843-51.

[89] Jakubowska K, Guzińska-Ustymowicz K, Famulski W, Cepowicz D, Jagodzińska D, Pryczynicz A. Reduced expression of caspase-8 and cleaved caspase-3 in pancreatic ductal adenocarcinoma cells. Oncol Lett. 19 Jan 2016; 11(3): 1879-84.

[90] Peter ME, Hadji A, Murmann AE, Brockway S, Putzbach W, Pattanayak A, et al. The role of CD95 and CD95 ligand in cancer. Cell Death Differ. 06 Feb 2015; 22(5): 585-86.

[91] Singh N, Lee YG, Shestova O, Ravikumar P, Hayer KE, Hong SJ, et al. Impaired death receptor signaling in leukemia causes antigen-independent resistance by inducing CAR T-cell dysfunction. Cancer Discov. Apr 2020; 10(4): 55267.

[92] Tong N, Zhang L, Sheng X, Wang M, Zhang Z, Fang Y, et al. Functional polymorphisms in FAS, FASL and CASP8 genes and risk of childhood acute lymphoblastic leukemia: A case-control study. Leuk Lymphoma. 31 Jan 2012; 53: 136066.

[93] Hays P. Review of therapeutic approaches for B-cell malignancies with immune checkpoint blockade and chimeric antigen receptor T-cell therapies: Development, benefits, and limitations. J Clin Invest Stud. 2019; 2. 